\title{
Better Therapies for Children: A Worldwide Search for Needed Human Resources
}

\author{
Stuart M. MacLeod ${ }^{1}$
}

Published online: 9 May 2015

(C) Springer International Publishing Switzerland 2015

\begin{abstract}
A point has been reached in the pursuit of optimal prescribing for infants, children and youth where global deficiencies in inter-professional communication are presenting a substantial barrier to progress. In an effort to remedy this situation, the International Alliance for Better Medicines for Children (IABMC) is seeking to create an international registry of engaged essential personnel. An open invitation is extended to all those who wish to partner with others in actively addressing the pressing global health challenge represented by gaps in the evidence base supporting safe and effective drug therapy for children of all ages. Respondents are invited to complete a brief survey at: https://www.surveymonkey.com/s/H3GKSHP.
\end{abstract}

Stuart M. MacLeod

smacleod@cfri.ca

1 Child \& Family Research Institute, BC Children's Hospital, 950 West 28th Ave, Vancouver, BC V5Z 4H4, Canada

\section{From the International Alliance for Better Medici- nes for Children}

The IABMC has initiated the development of an asset map that will include as broad a cross-section as possible of researchers, educators and clinicians committed to the optimization of pediatric drug therapy.

Once the directory is complete, an in-depth analysis will be undertaken to identify human resource shortfalls and to highlight gaps in expertise essential for evaluation of therapies in child health worldwide.

All those interested in being included in the asset map are invited to complete a brief survey at: https:// www.surveymonkey.com/s/H3GKSHP.

A point has been reached in the pursuit of optimal prescribing for infants, children and youth where global deficiencies in inter-professional communication are presenting a substantial barrier to progress. In an effort to remedy this situation, the International Alliance for Better Medicines for Children (IABMC) is seeking as described below to create an international registry of engaged essential personnel. This editorial offers an open invitation to all those who may wish to partner with others in actively addressing the pressing global health challenge represented by gaps in the evidence base supporting safe and effective drug therapy for children of all ages.

Worldwide, there is increasing recognition that children deserve a higher degree of evidence-based therapy than has generally been provided in the past [1-3]. There can no 
longer be any possible justification for pursuing an exacting standard of validation for innovative drug treatments in adults while ignoring the ongoing treatment of childhood disorders with drugs chosen and dosed through extrapolation of studies conducted often exclusively in older patient populations. Worse yet, pediatric therapeutic choices are often made on the basis of recommendations found only in the grey literature or supported by clinician instinct passed on informally. Even the assessment of drug safety in the pediatric population is usually conducted in a more superficial fashion than in adult medicine, despite the fact that the risk of unanticipated drug toxicity is considerably higher in an environment where off-label use is common [4].

All too often the rights of children to treatment on the basis of better therapeutic information that takes into account what is known about developmental pharmacology and toxicology go unrecognized. Therapy must be based wherever possible on high-quality research and the achievement of sound choices can only come with the increasing development of innovative, flexible research methods that are adaptable to employment in the study of frequently uncommon or rare childhood disorders [3].

In September 2014, an important report from John McArthur of the Brookings Institution offered some grounds for optimism, recognizing significant progress made towards improving child mortality worldwide [5]. There is no single factor to account for the overall improvement in child mortality and certainly the Millennium Development Goals deserve their share of credit [6]. Nonetheless, improvement in the overall approach to treatment of children with drugs and vaccines has contributed greatly and will likely continue to be an important factor in the future.

The potential of new drug therapies in pediatrics will never be fully recognized without the achievement of improved randomized trials of therapies in the child population with particular focus on adaptive and alternative protocol designs [3]. It is equally clear that much of the needed effort in this regard must be focused on developing countries where a majority of the world's children reside. In 2013 the world's total child population (0-14 years) was 1.85 billion and, of that number, 0.33 billion were resident in low-income countries, with 1.342 billion in middle-income countries [7].

Improved performance in pursuit of better drug therapy for children will remain elusive without a substantial advance in clinical investigation planning and partnership among the clinicians, educators, and researchers worldwide who share relevant skills and interests. Despite amazing progress in improving pediatric therapeutics in the last two decades, there is still no reliable comprehensive catalogue of individuals capable of contributing to essential clinical investigation and knowledge transfer activities. It seems evident that now is the time to make a commitment to the development of an adequate human resource database to serve the therapeutic needs of all children but with particular emphasis placed on the developing world [8-11].

Towards that end, following an international meeting in Shanghai in 2006 [12], the IABMC was created with the goal of coordinating international clinical research efforts and identifying human resource needs. The Alliance is incorporated as a not-for-profit organization in Canada and aspires to a role in promoting and coordinating international activities relevant to the pursuit of evidence-based therapy for children. As part of that process, the Alliance is currently working with international partners to develop the asset map described in this editorial. We are seeking clinicians, researchers, and educators in all parts of the world whose activities are focused on pediatric pharmacology, pharmacy, and toxicology. The hope is that an inclusive inventory will be developed, helping to guide those interested in pediatric therapeutics and drug safety to appropriate expertise ranging from research through clinical practice to knowledge transfer. Where deficiencies in needed expertise exist, they will be highlighted.

The asset map's scope should encompass all methodologic disciplines, including pharmaceutical and implementation sciences, statistics, pharmacokinetics, pharmacodynamics, pharmacometrics, pharmacoepidemiology, health outcomes research and regulatory science. Representation from those with expertise in ethical review of pediatric trials will be welcomed. Once compiled, the inventory will be openly available to all who share a commitment to improved drug treatment of children. Although individuals employed in the private sector are encouraged to respond, it is not intended that the asset map will be made available for commercial purposes unless the specific consent of listed individuals is obtained in future.

In attempting to identify a comprehensive sample of the world's expertise, the Alliance is working closely with organizations that have already established networks of pediatric pharmacy and clinical pharmacology (or other relevant sub-speciality medicine interests) in all parts of the world. Many of the readers of Pediatric Drugs will already have received an invitation to complete a survey of their involvements; however, it is our wish to be as inclusive as possible and we invite any readers of this commentary to add their input by responding to the asset map survey as described above.

This is the starting point for what should become a consistent, continuing effort to maintain a current and freely available listing of individuals committed, in keeping with their diverse skills, to the pursuit of better drug therapy of children from birth to adolescence.

Conflict of interest The author declares no conflict of interest. 


\section{References}

1. MacLeod S. Developing better medicines for children: addressing international priorities. Am Pharm Rev. 2012;15:74-80.

2. Institute of Medicine. Safe and effective medicines for children: pediatric studies conducted under the Best Pharmaceuticals for Children Act and The Pediatric Research Equity Act. Washington, DC: The National Academies Press; 2012.

3. Council of Canadian Academies. Improving medicines for children in Canada: the expert panel on therapeutic products for infants, children and youth. Ottawa, ON; 2014.

4. Kimland E, Odind V. Off-label drug use in pediatric patients. Clin Pharmacol Ther. 2012;91:796-801.

5. McArthur J. Brookings Institution. Seven million lives saved: under-5 mortality since the launch of the Millennium Development Goals. September 2014. Global working paper 72. http:// www.brookings.edu/research/papers/2014/09/under-five-childmortality-mcarthur. Accessed 02 May 2015.

6. MacLeod S, Rane A. Seeking improved global child health: progress toward millennium development goal 4. Pediatr Drugs. 2014;16:101-3.
7. The World Bank. World development indicators: population dynamics. 2014. http://wdi.worldbank.org/table/2.1. Accessed 02 May 2015.

8. Duke T, Fuller D. Randomised controlled trials in child health in developing countries over 11 years. Arch Dis Child. 2014;99:615-20.

9. Berkley JA. Randomized trials in developing countries. Arch Dis Child. 2014;99:607-8.

10. Le Doare K, Barker CIS, Irwin A, Sharland M. Improving antibiotic prescribing for children in the resource-poor setting. Br J Clin Pharmacol. 2015;79:446-55.

11. MacLeod S, Hill S, Koren G, Rane A, editors. Optimizing treatment for children in the developing world. Springer, Switzerland. 2015. doi:10.1007/978-3-319-15750-4_30.

12. MacLeod S, Peterson R, Wang Y, Li Z, Gui Y, Schaller J. Challenges in international pediatric pharmacology: a milestone meeting in Shanghai. Pediatr Drugs. 2007;9:215-8. 